\title{
Histopathological effects of tobacco leaf extract on juvenile African catfish muscle
}

\author{
Nwamba, H. O ${ }^{1}$, Nwakanma, H. O²., Uzoho, A. $\mathrm{M}^{2}$. , Esione, C. B. ${ }^{2}$. \\ ${ }^{1}$ Applied Biology and Biotechnology Department, Enugu State University of Science and Technology, Enugu, Nigeria. \\ ${ }^{2}$ Materials and Energy Technology Department, Projects Development Institute (PRODA), P.M.B. 01609, Enugu, Nigeria \\ *Correspondence: chinelookafor1@gmail.com
}

\begin{abstract}
In Subsahara Africa, most indigenous small and medium scale catfish farmers have relied on the effectiveness of tobacco leave (Nicotiana tobacum) to treat ponds before stocking. Nicotiana tobacum in solution eliminates microbes and toxins which can be harmful to fish health. As a follow up, it is necessary to investigate if a left over minute concentration, has adverse effect on aquatic health. For this reason, the effect of ethanol extracts of Nicotiana tobacum leaf on the histopathology of muscles of juvenile fresh water Clarias gariepinus (African catfish) was investigated. The fish were acclimated for 14 days. Sublethal concentrations $(0.25 \mathrm{mg} / \mathrm{l}, 0.50 \mathrm{mg} / \mathrm{l}, 0.75 \mathrm{mg} / \mathrm{l}, 1.00 \mathrm{mg} / \mathrm{l}$ and $1.25 \mathrm{mg} / \mathrm{l})$ of ethanol leaf extract of Nicotiana tobacum in aqueous media were prepared. Each aquarium had 10 juveniles of mean length $6.9 \pm 0.62 \mathrm{~cm}$. After initial acclimation, the fish was exposed to the media for 96 hours. Histopathological micrograph of the catfish muscle tissue exposed to sublethal concentrations of Nicotiana tobacum indicate breakage of myofibrils, disintegrated myotomes, bunding of myotomes, lesions, hemorrhage and tissue inflammation. Preliminary Scanning electron microscopy of the ethanol extract of Nicotiana tobacum leaves showed the micro surface structure (morphology) and elemental composition of the extract. Results obtained from this work indicate that Nicotiana tobacum used as a biological control to eradicating predators and unwanted organisms in the ponds by local farmers in place of agrochemicals, if not controlled can exact varying degree of negative histopathological effect on the muscles of juvenile African cat fish, Clarias gariepinus.
\end{abstract}

Keywords: Clarias gariepinus, Nicotiana tobacum, histopathology

\section{Introduction}

Presently, the world is a home for about seven billion people. It is projected to increase to about nine billion in the year 2050. Various regional and national governments will have to work harder to solve some pressing humanitarian needs such as affordable shelter, energy, food, health care, transport, clean water and recreation. Among these needs, affordable, nutritious food (hunger reduction) could be considered most important. One of the ways to achieve this is the provision of meat through fisheries.

\section{Literature Review}

Fisheries and aquaculture play a significant role in global food supplies, and demand for high-quality aquatic protein is expected to increase substantially as income levels rise and Asia and African populations expand ${ }^{[1]}$. The annual fish demand in Nigeria as at 2012 is 2.66 million metric tonnes, with supply being only 1.32 million metric tonnes ${ }^{[2]}$.

Out of this figure, local production is 0.62 million metric tonnes while 0.7 million metric tonnes is from importation. In developing countries such as Nigeria,

some of the factors that caused the increase in demand for fish are substantial improvement in citizens personal income, comparative cost advantage of fish over beef, poultry and pork meat, and change in personal preferences. Fish is very important in the diet of many Nigerians, high in nutritional value with complete array of amino acids, vitamins and minerals ${ }^{[3]}$. In addition, fish products are relatively cheaper compare to beef, pork and other animal protein sources in the country ${ }^{[4]}$. Fish contribute more than $60 \%$ of the world supply of protein, especially in the developing countries [5]. Fish species commonly cultured for food include Clarias and Heterobranchus spp. (catfish), Tilapia spp. (Tilapia),Cyprinus carpio (Common carp),Heterotis niloticus (Slap water) ${ }^{[2]}$. This culturable species usually grow to a minimum acceptable marketable size in a reasonable growing period (usually between 4-9 months of culture) depending on the production system. Among other fish species, african catfish (Clarias gariepinus) is one of the fish species which have been successfully grown or cultured in environments outside its natural dwelling habitat. Positive attributes such as resistance to diseases, high fecundity, and ease of larval production in captivity make it of commercial importance in aquaculture ${ }^{[6]}$. Also, this fish species have the ability to survive fairly poor water condition and in the absence of improvised aeration system in semi-intensive system.

[Received 01 March 2020; Accepted 27 May 2019; Published (online) 30 June 2020] Publisher's Note: RCLSS stays neutral regard to jurisdictional claims published maps (c) (1) 
In semi-intensive system of farming, the management of water pond weeds is one of the most important aspects of a successful production system ${ }^{[7]}$. However, the presence of predatory fishes; 'weed' fishes, such as Chaoborus larva, tadpoles, frogs and leeches in fish culture ponds is a serious problem in aquaculture, which is due to their faster growth rate, as they share and better utilize cultured habitats and their food [8]. This therefore justifies the application of an effective biocide to stop the activities of pond or freshwater weeds before stocking. Tobacco leave have been found useful to this effect in Nigeria catfish aquaculture.

The use of tobacco leaf is due to its inexpensiveness, local availability and easier degradability ${ }^{[9]}$. The most valuable part / active ingredient of tobacco leave, is the nicotine, lipophilic in nature with high solubility in membrane lipid and fast influx into cells ${ }^{[10]}$. Nicotine $\left(\mathrm{C}_{5} \mathrm{H}_{4} \mathrm{~N}\right)-\mathrm{CH}-\left(\mathrm{CH}_{2}\right)_{3}-\mathrm{N}-$ $\left(\mathrm{CH}_{3}\right)$ is made up of pyridine and pyrroliding ring. Nearly all the nicotine is produced in the root and transported to the leaves for storage. It is soluble in water, alcohol, chloroform, ether, kerosene and some fixed oils ${ }^{[11]}$. It is easily absorbed in body and can penetrate the epithelial and blood cells ${ }^{[12]}$. Despite the effective use of tobacco leaf dust, its ecotoxic properties are of interest to ecotoxicologists. As a rule, pesticides of plant origin should not be used directly in freshwater bodies unless their toxicity and sublethal longterm effect on nontarget animals, sharing the habitat with the target animals, have been determined ${ }^{[13]}$.

\section{Methodology}

\section{Tobacco leave collection and preparation}

The fresh leaves of nicotina tobaccum were collected from local traders in enugu. The fresh leaves of $(1 \mathrm{~kg})$ were collected and washed well to remove any adhering foreign particles and soil materials. The washed leaves were oven dried at $48^{\circ} \mathrm{C}$ for $36 \mathrm{~h}$ to prevent enzyme action. After drying, it was coarsely powdered in preparation for ethanol extraction using soxhlet apparatus.

\section{Preparation of ethanol tobacco extract}

Crude plant extract was prepared by Soxhlet extraction. Ethanol was used for the extraction. Sample (100g of tobacco leave powder) was weighed per time into a semi-permable cotton material and placed into the timble of a $500 \mathrm{ml}$ sohxelet extractor. $400 \mathrm{ml}$ of ethanol was measured into a $500 \mathrm{ml}$ flat bottom round flask. The sohxelet with the extraction timble containing the sample in a semi-permable membrane was connected with the condenser which was fitted to the flat bottom round flask containing the ethanol. The sohxelet extraction system was heated in a water bath at $100{ }^{\circ} \mathrm{c}$ while water was allowed to circulate at the outer jacket of the condenser. The extraction was discontinued when phytochemicals were completely extracted from the sample. The used sample in the semi permeable membrane was discarded, while the phytochemical and ethanol mixture in the flat bottom flask was filtered using Whatmann no. 1 filter paper. The solution was concentrated at $48^{\circ} \mathrm{c}$ in water bath and stored in the refrigerator at $4^{\circ} \mathrm{c}$ until use.

\section{Fish sample collection and acclimation}

Juveniles of Clarias gariepinus were bought from a fish farm in Enugu, Enugu State. The juveniles were transported in two aerated polythene bags to the laboratory in the early hours of the morning $(8: 00 \mathrm{am})$. The water to be used for stocking of the juveniles was dechlorinated by exposing it to sun for a period of $48 \mathrm{~h}$. The Clarias gariepinus juveniles were kept in a plastic aquarium tank and allowed to acclimatize to laboratory conditions for a period of 14 days in an already dechlorinated tap water. The juveniles were fed twice daily using coppen commercial supplementary feed (42\% protein content). The water was change daily to prevent accumulation of toxic waste. Experimentation was carried out under ambient laboratory conditions. Feeding of the juveniles stop a day before the bioassay.

\section{Bioassay}

10 liter aquaria were used for the study. Each aquarium has a known concentration of nicotina tobaccum prepared in triplicates. Preliminary tests were carried out at first to determine suitable range of concentration for the bioassay experiment. The concentration ranges chosen for the ethanol extract of nicotina tobaccum after preliminary test were: 0.25 , $0.50,0.75,1.00$ and $1.25 \mathrm{mg} / \mathrm{L}$, respectively.

These concentrations were prepared in 10 litres of water from same source used for acclimation. Each aquarium had 10 juveniles of mean length $6.9 \pm 0.62 \mathrm{~cm}$. Also prepared is the control media (in triplicate) which had no nicotina tobaccum extract. Precautionary measure to avoid stress on the fish was taken while distributing them to the various plastic aquaria. This was achieved by the use of hand net. Fish samples were collected at intervals of 24, 48, 72 and 96 for muscular histopathological analysis.

\section{Histopatological studies}

Tissue cutting: various tiny sections of the fish tissue (muscle) were cut out using forceps and dissection knife. The tissues were placed individually in cassettes.

Tissue processing: the cut tissues placed in cassettes were immersed in a fixative. The fixative used is formaldehyde. The cassettes were allowed to sit in the fixative for 24 hours. After 24 hours, the cassettes were removed from the fixative. Dealcohol: the tissues in cassettes were immersed in different concentrations of alcohol (ethanol). They were immersed in the alcohol in ascending concentration. They were initially immersed in alcohol 70 vol. \% for 15 minutes, 90 vol. \% for 15 minutes and lastly 100 vol. \% for 30 minutes.

Infiltration: the tissues were immersed in 2 xylene solutions (each within 20 minutes)

Impregnation: the tissues were immersed in paraffin wax bath at $55-60^{0 \mathrm{c}} \mathrm{c}$ for 45 minutes. This was done with two different paraffin wax solutions successively. After impregnation with 
paraffin wax, the tissues were embedded in a paper boat and allowed to cool.

Microtomy: the tissues were cut individually into ribbons using the microtom. The formed ribbons were placed in water bath to get moistened for few minutes. Fix on slides: rectangular glass slides were laced with adhesive and 3/4 portion of it placed in the water bath to carefully place the moistened ribbons on them with the aid of forceps.

After this, the fixed slides were incubated at $65^{\circ} \mathrm{c}$ for 30 minutes to remove excess paraffin.

Staining: the slides were immersed in xylene for 30 minutes. The immersion was repeated in new xylene for another 30 minutes. The slides were immersed repeatedly in different concentrations of ethanol in descending order; $100 \%$ ethanol for 10 minutes (2 times), $90 \%$ ethanol for 5 minutes, $70 \%$ ethanol for 1 minute, $30 \%$ ethanol for 1 minute. After the immersions, they were rinsed in phosphate-buffered saline (PBS) for 5 minutes and excess liquid wiped from around the tissue. The slides were stained in $200 \mathrm{ml}$ hematoxylin solution and incubated at room temperature for 5 minutes. It was washed in running water from reverse side and rinsed in PBS for 5 minutes. Excess liquid was wiped away from around the tissue. Also the slides were stained in $400 \mathrm{ml}$ eosine solution for 30 seconds. Hematoxylin and eosin were applied using a micro pipette. They were washed in running tap water from reverse side and rinsed in PBS for 5 minutes. They were dehydrated in absolute ethanol in two changes of 2 minutes each and subsequently cleared in xylene, two changes of 10 minutes each. The stained tissues in slides were allowed to stand and air dried. A drop of Canada Balsam were placed on the stains and covered with cover slip.

Microscopy: the slides were viewed using a monocular microscope connected to a lap top computer for viewing and image saving. The microscope and computer systems were interfaced using a soft ware programme (top view). The slides were placed on the stage and fine and coarse adjustment nubs were used to obtain best images.

\section{Scanning electron microscopy (SEM)}

Scanning electron microscope (Phenom ProX) manufactured by Phenomworld Eindhoven, the Netherlands, was used to determine the micro surface structure and elemental composition of the ethanol extract of tobacco leave.

RESULTS AND DISCUSSION

Scanning electron microscope (SEM) analysis was done on the ethanol extract of tobacco leaf (Nicotiana tobacum) to determine the micro surface structure (morphology) and elemental composition of the extract

\begin{tabular}{lllll}
\hline $\begin{array}{l}\text { Element } \\
\text { Number }\end{array}$ & $\begin{array}{l}\text { Element } \\
\text { Symbol }\end{array}$ & $\begin{array}{l}\text { Element } \\
\text { Name }\end{array}$ & $\begin{array}{l}\text { Atomic } \\
\text { Conc. }\end{array}$ & $\begin{array}{l}\text { Weight } \\
\text { Conc. }\end{array}$ \\
6 & $\mathrm{C}$ & Carbon & 93.65 & 87.21 \\
17 & $\mathrm{Cl}$ & Chlorine & 1.14 & 3.14 \\
19 & $\mathrm{~K}$ & Potassium & 0.87 & 2.63 \\
8 & $\mathrm{O}$ & Oxygen & 1.95 & 2.41 \\
14 & $\mathrm{Si}$ & Silicon & 0.39 & 0.84 \\
7 & $\mathrm{~N}$ & Nitrogen & 0.77 & 0.84 \\
13 & $\mathrm{Al}$ & Aluminium & 0.33 & 0.70 \\
16 & $\mathrm{~S}$ & Sulfur & 0.17 & 0.42 \\
20 & $\mathrm{Ca}$ & Calcium & 0.14 & 0.42 \\
12 & $\mathrm{Mg}$ & Magnesium & 0.22 & 0.41 \\
26 & $\mathrm{Fe}$ & Iron & 0.08 & 0.36 \\
15 & $\mathrm{P}$ & Phosphorus & 0.14 & 0.33 \\
11 & $\mathrm{Na}$ & Sodium & 0.16 & 0.28 \\
\hline
\end{tabular}

Table 1: Elemental analysis of ethanol extract of Nicotiana tobacum leaf from SEM.

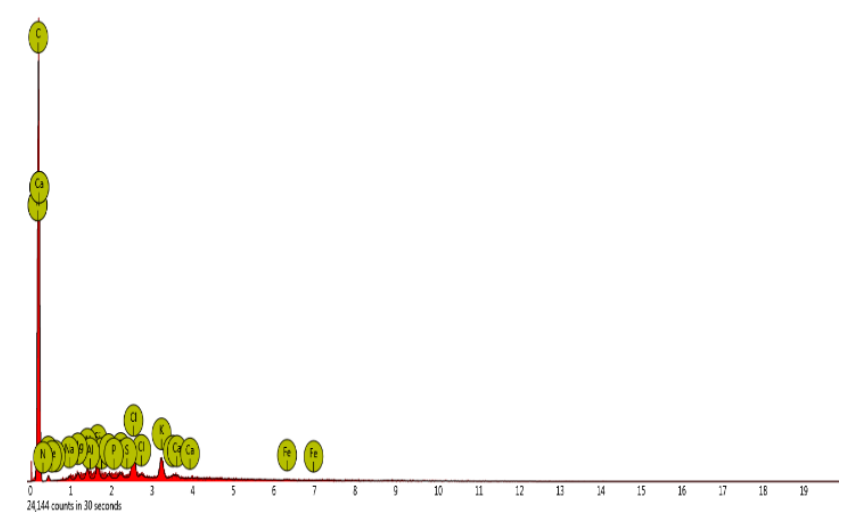

Fig. 1: Graph of elemental analysis of ethanol extract of Nicotiana tobacum leaf from SEM.

Table 1 and figure 1 are representations of elemental analysis of ethanol extract of tobacco leaf. A total of 13 elements were identified. They include carbon, chlorine, potassium, oxygen, silicon, nitrogen, aluminium, sulfur, calcium, magnesium, iron, phosphorus and sodium. Of all these elements, carbon with elemental number 6 has a greater part of total weight concentration which is $87.21 \%$. This is characteristic of most plant materials. 


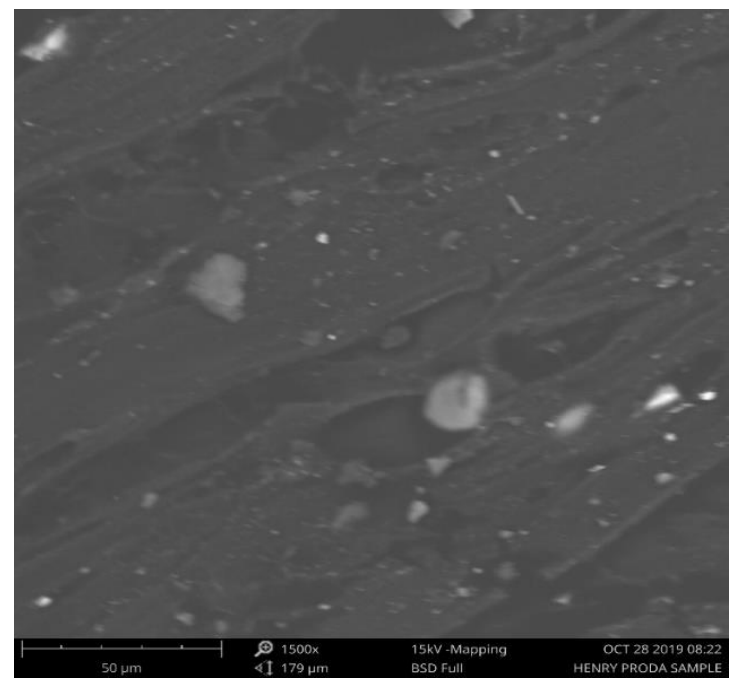

Fig. 2: Micrographs of SEM analysis of ethanol extract of Nicotiana tobacum leaf from SEM.

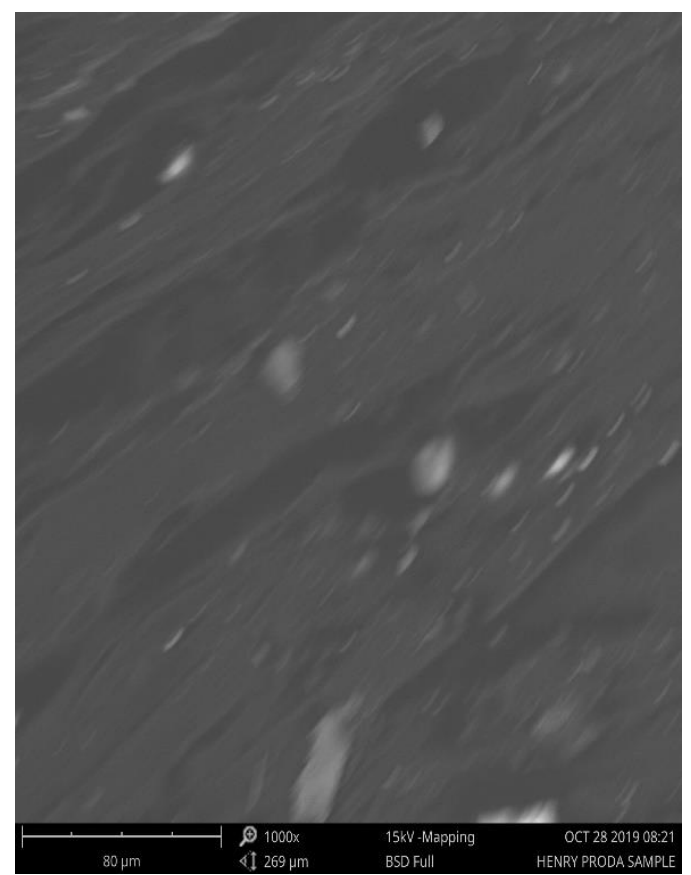

It was necessary to employ SEM technology to study the leaf extract following the obvious change in morphology of the extract from the initial form. The micrograph was studied in different magnifications namely $\times 500, \times 1000$ and $\times 1500$. The extract appears to have a smooth texture which is an obvious characteristic of pasty extracts. A cross section of the micrograph shows the presence of pores embedded in the matrix. The dense, compact texture of the extract confers higher concentration.

\section{Histopathological Analysis}

Micrographs for histopathological analysis of muscle of juvenile Clarias gariepinus were examined to determine the effect of varied concentrations of ethanol extract of Nicotiana tobacum on the muscle of the fish. The photomicrograph of the muscle initially depicts the presence of normal myotomes with unevenly spaced septum. On exposure to sublethal concentrations of Nicotiana tobaccum extract, broken myofibrils, disintegrated myotomes, bunding of myotomes, leisions, hemorrhage and inflammation were observed at different concentrations and levels of exposure.

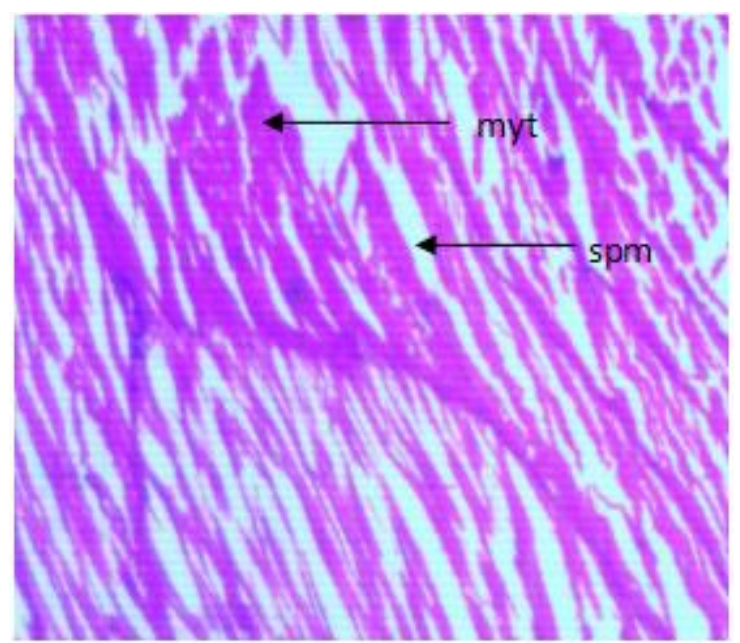

Fig. 3: Muscle section in control group (24 hours)

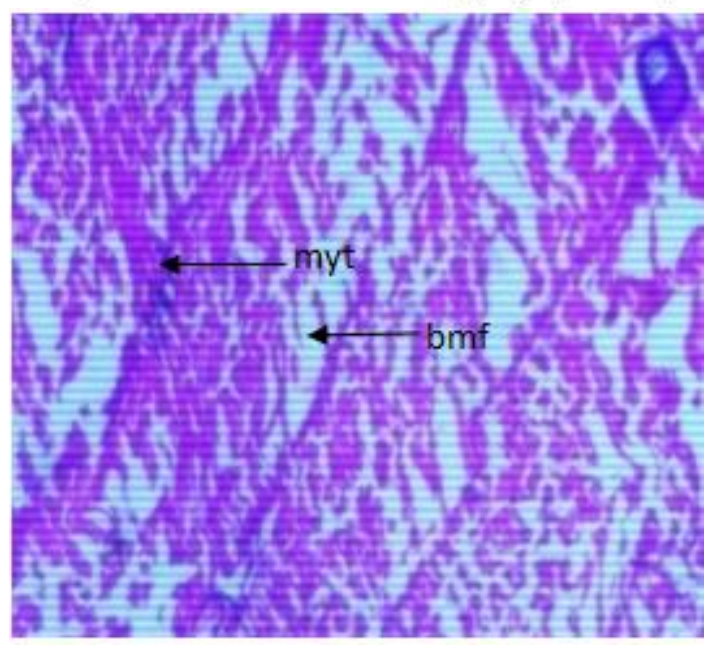

Fig. 4: Muscle section in control group (48 hours) 


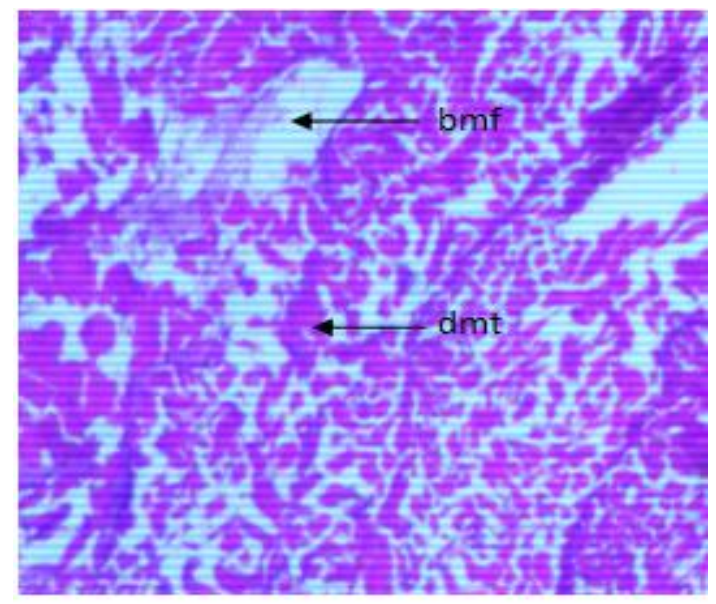

Fig. 5: Muscle section in control group (72 hours)

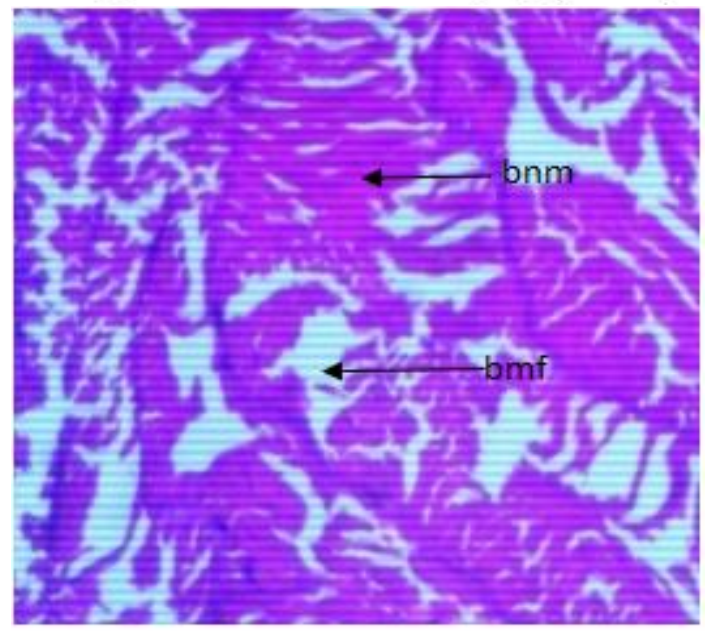

Fig. 6: Muscle section in control group ( 96 hours)

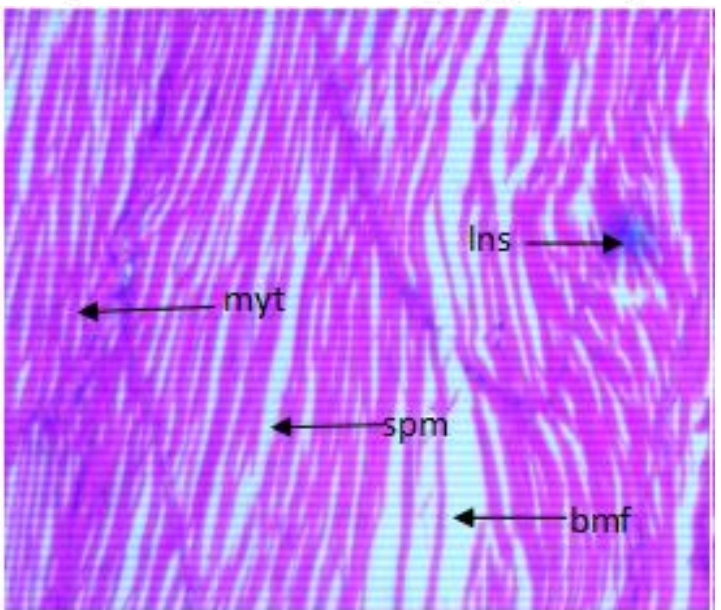

Fig. 7: Muscle section in group treated with $0.25 \mathrm{mg} 1$ Nicotina tobaccum leave extract (24 howrs)

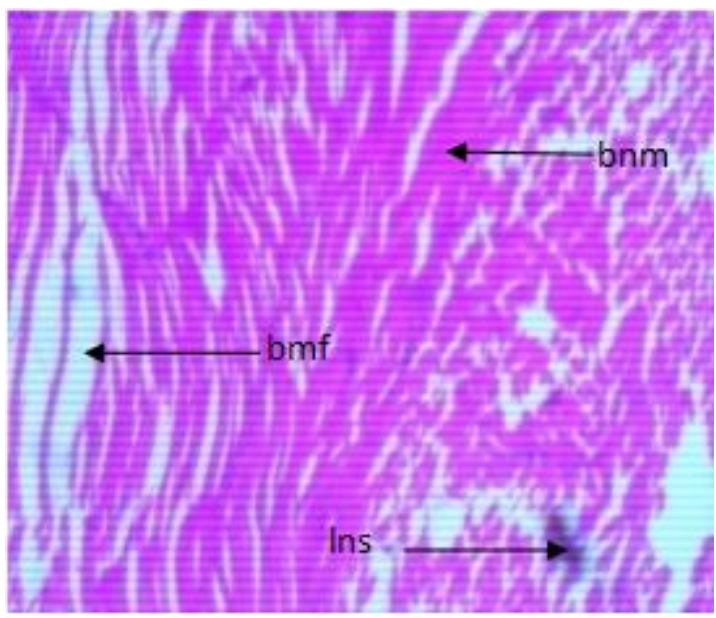

Fig. 8: Muscle section in group treated with $0.25 \mathrm{mg} /$ Nicotina tobaccum leave extract ( 48 hours)

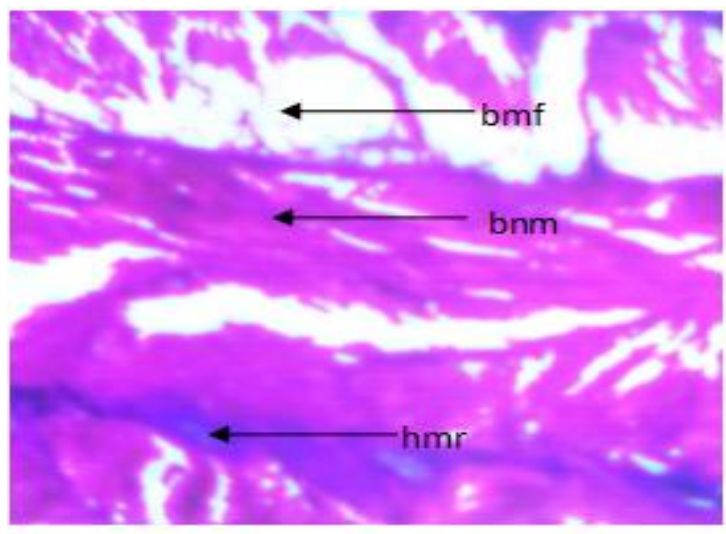

Fig. 9: Muscle section in group treated with $0.25 \mathrm{mg} / 1$ Nicotina tobaccwn leave extract ( 72 hours)

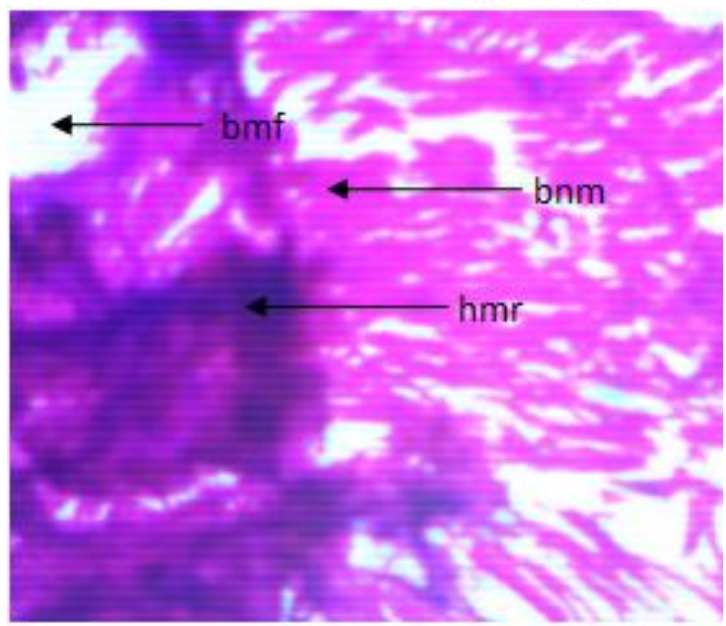

Fig. 10: Muscle section in group treated with $0.25 \mathrm{mg} /$ Nicotina tobaccum leave extract ( 96 hours) 


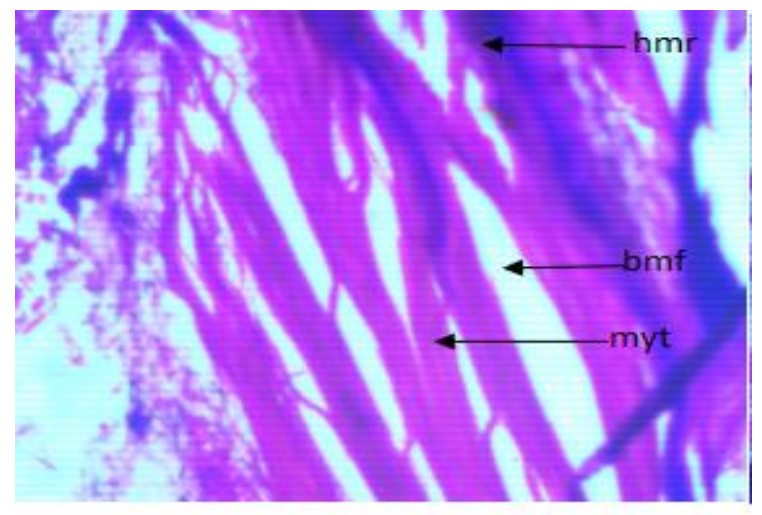

Fig. 11: Muscle section in group treated with $0.50 \mathrm{mg} /$ Nicotina to baccum leave extract ( 24 hours)

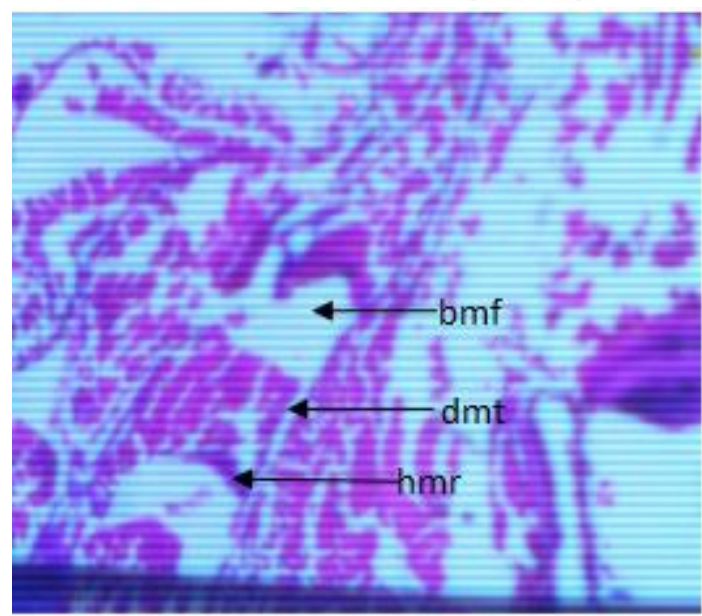

Fig. 12: Muscle section in group treated with $0.50 \mathrm{mg} /$ Nicotina tobaccum leave extract (48 hours)

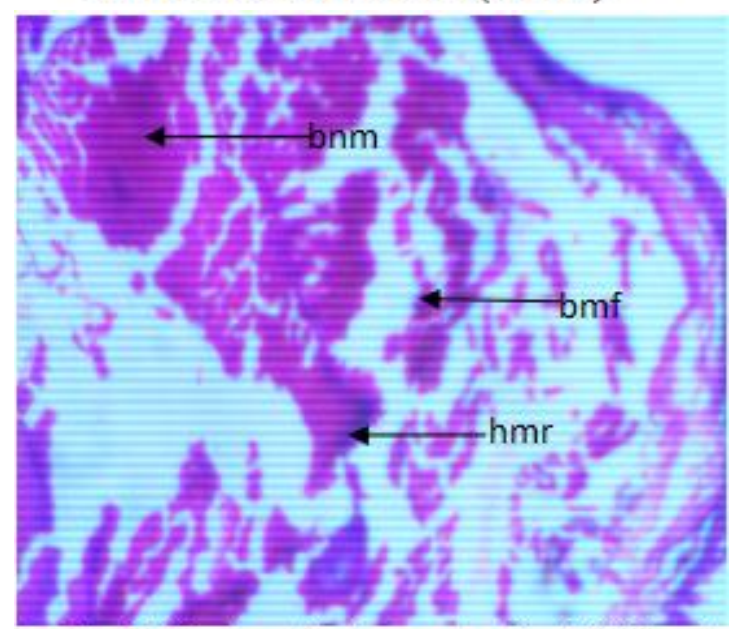

Fig.13: Muscle section in group treated with $0.50 \mathrm{mg} / 1$ Nicotina tobaccum leave extract ( 72 hours)

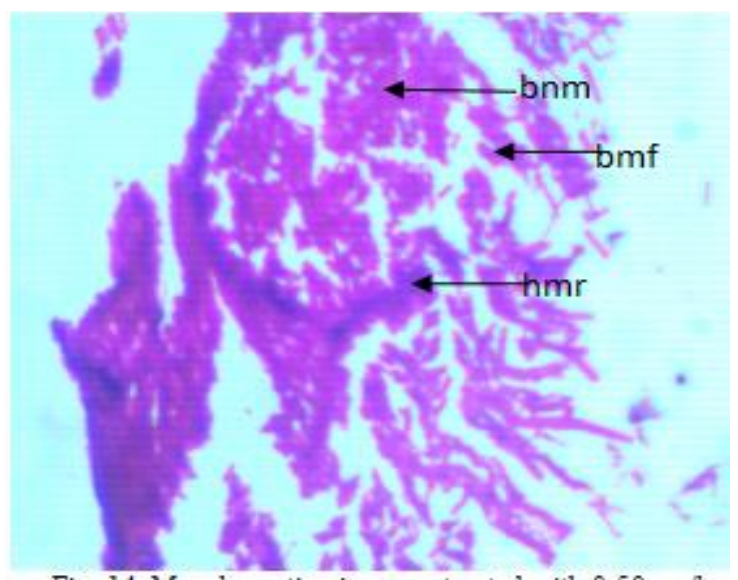

Fig. 14: Muscle section in group treated with $0.50 \mathrm{mg} /$ Nicotina tobaccum leave extract ( 96 hours)

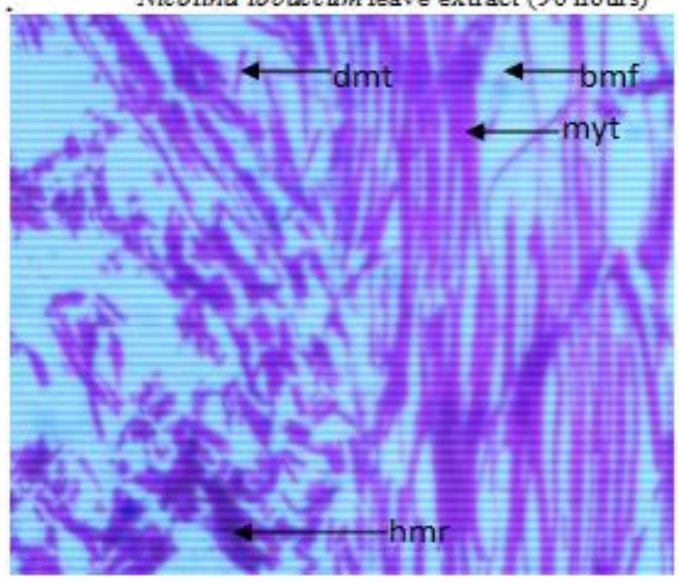

Fig. 15: Muscle section in group treated with $0.75 \mathrm{mg} / 1$ Nicotina tobaccwn leave extract ( 24 hours)

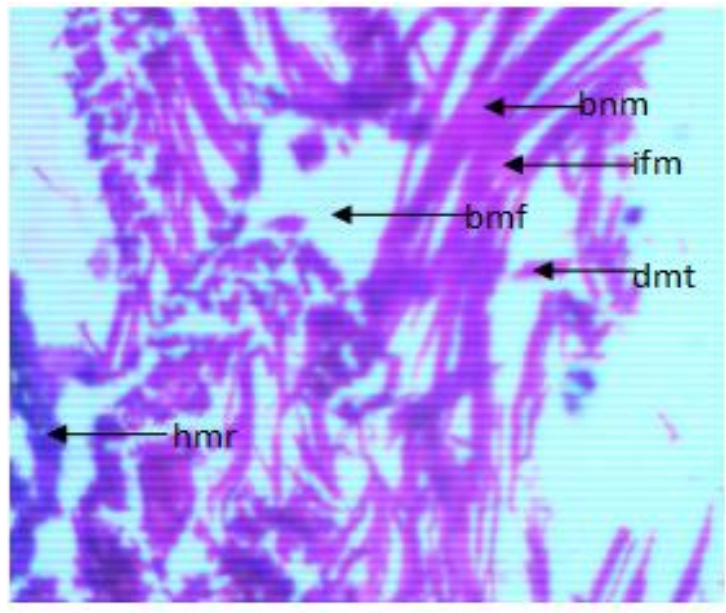

Fig. 16: Muscle section in group treated with $0.75 \mathrm{mg} /$ Nicotina to baccum leave extract ( 48 hours) 


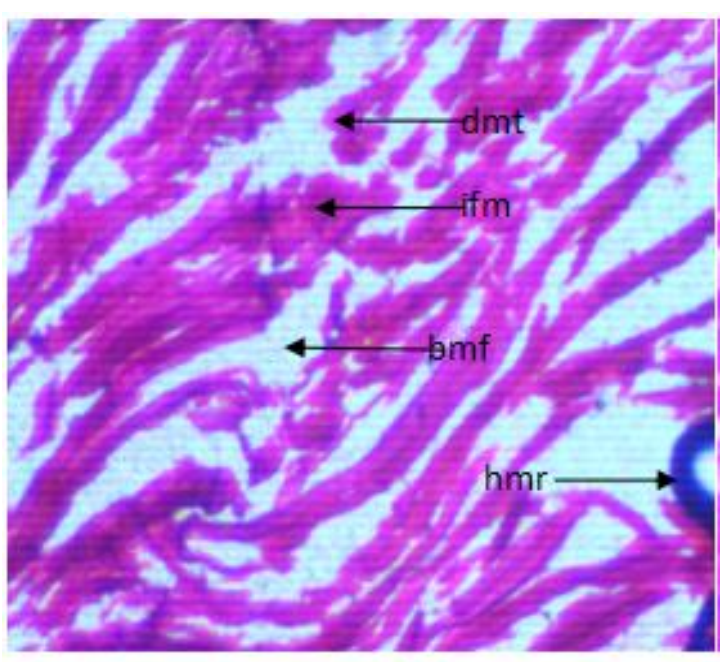

Fig. 17: Muscle section in group treated with $0.75 \mathrm{mg} /$ Nicotina tobaccwn leave extract ( 72 hours)

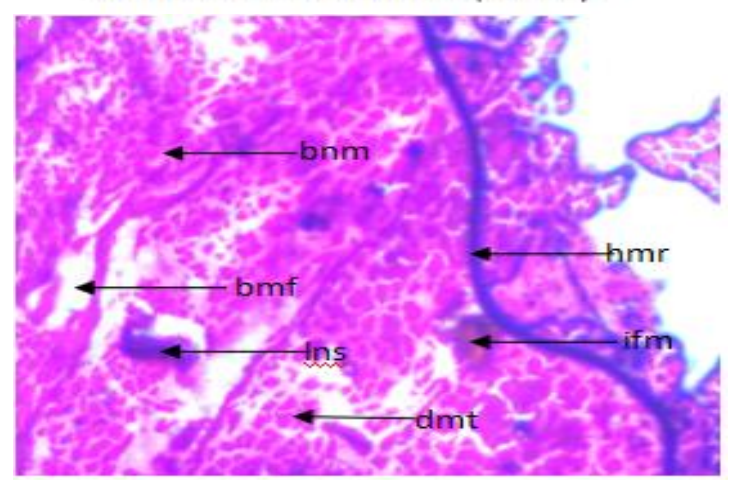

Fig. 18: Muscle section in group treated with $0.75 \mathrm{mg} / 1$ Nicotina tobaccum leave extract ( 96 hours)

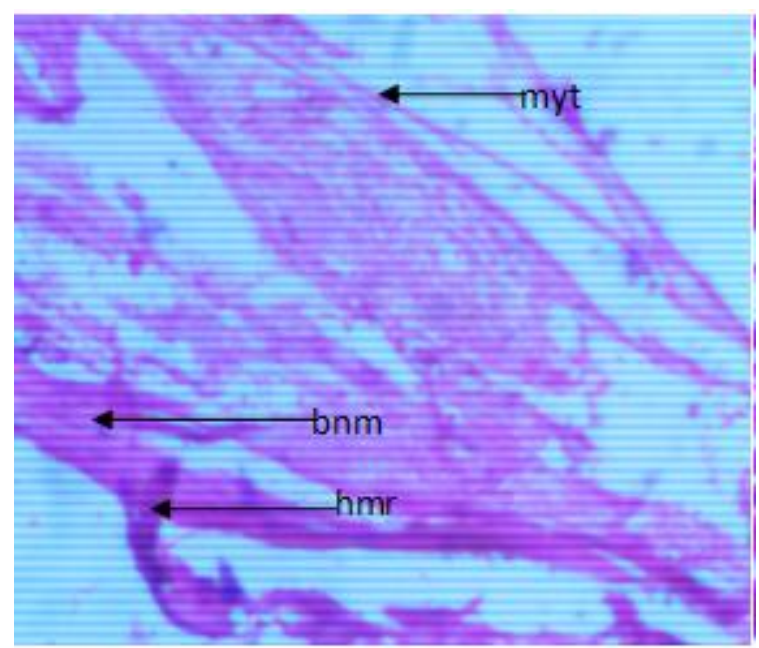

Fig. 19: Muscle section in group treated with $1.00 \mathrm{mg} /$ Nicotina tobaccum leave extract ( 24 hours)

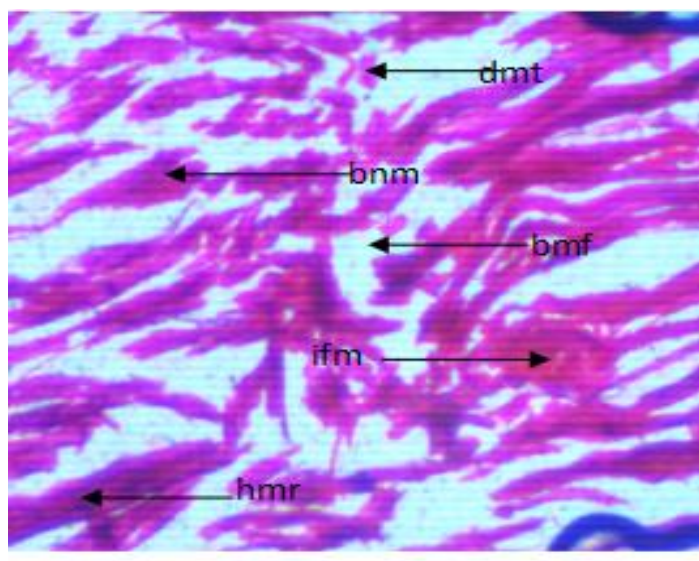

Fig. 20: Muscle section in group treated with $1.00 \mathrm{mg} / 1$ Nicotina tobaccum leave extract ( 48 hours)

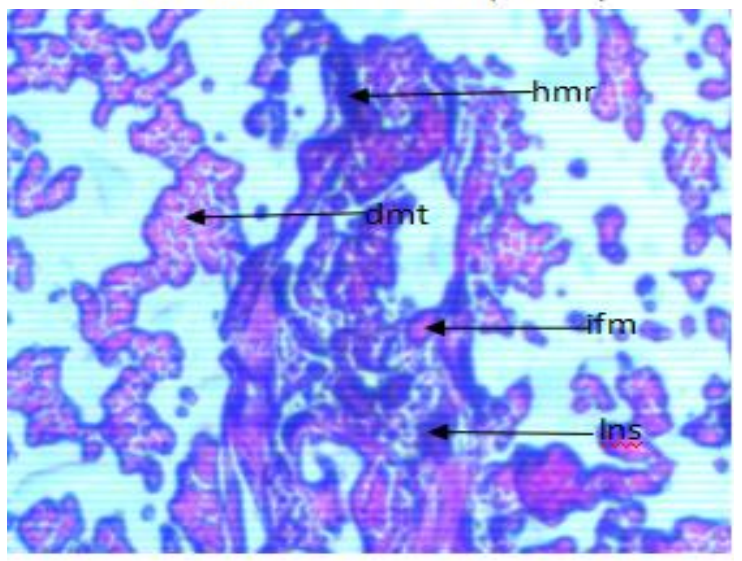

Fig. 21: Muscle section in group treated with $1.00 \mathrm{mg} / 1$ Nicotina tobaccum leave extract ( 72 hours)

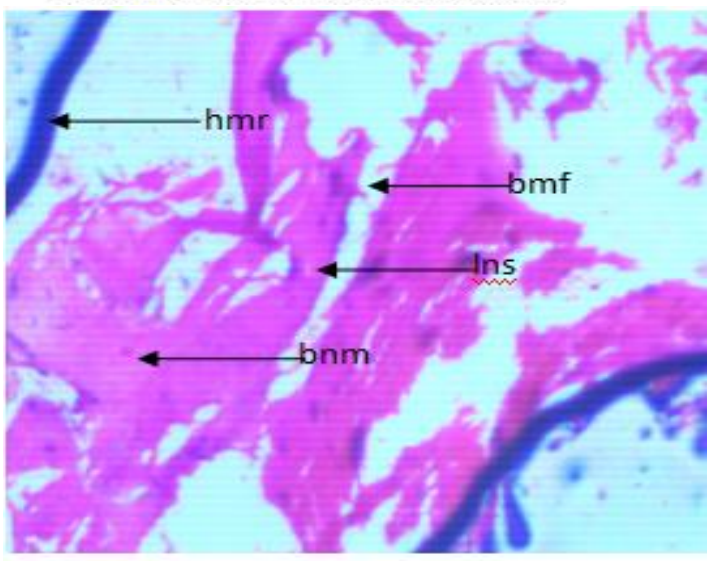

Fig. 22: Muscle section in group treated with $1.00 \mathrm{mg} / 1$ Nicotina tobaccum leave extract ( 96 hours) 


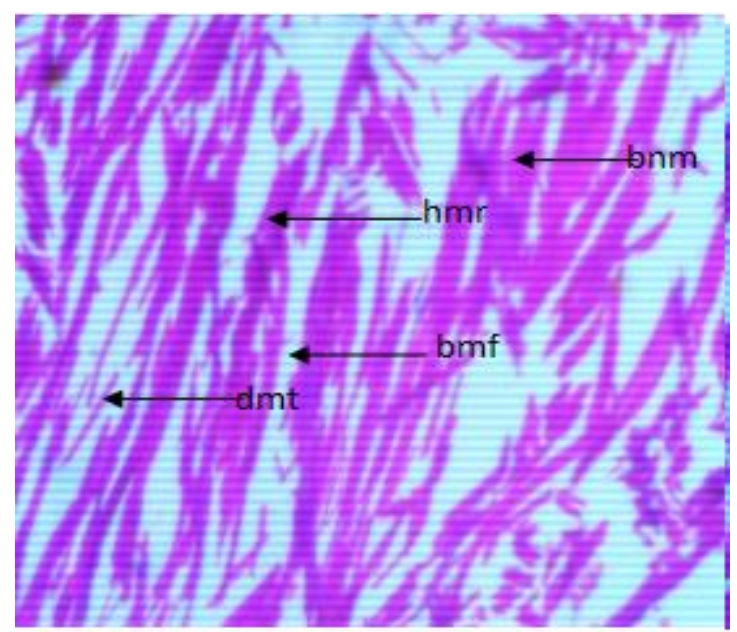

Fig. 23: Muscle section in group treated with $1.25 \mathrm{mg} / 1$ Nicotina tobaccum leave extract (24 hours)

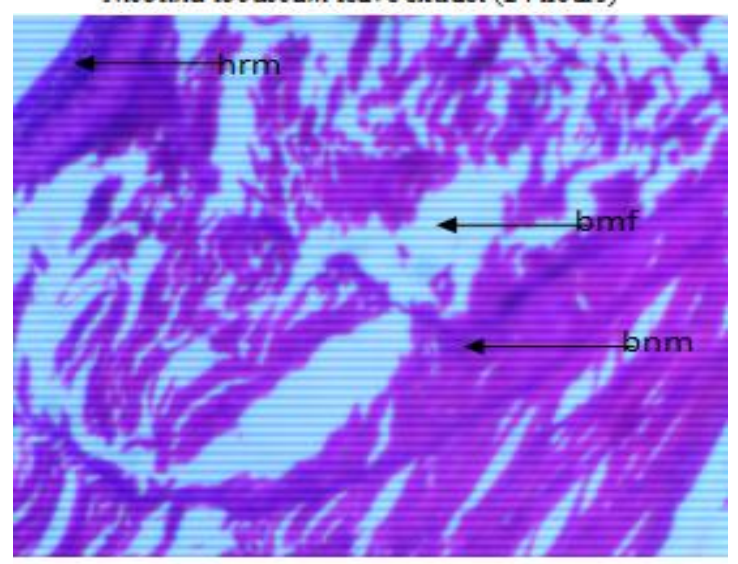

Fig. 24: Muscle section in group treated with $1.25 \mathrm{mg} / 1$ Nicotina tobaccun leave extract ( 48 hours)

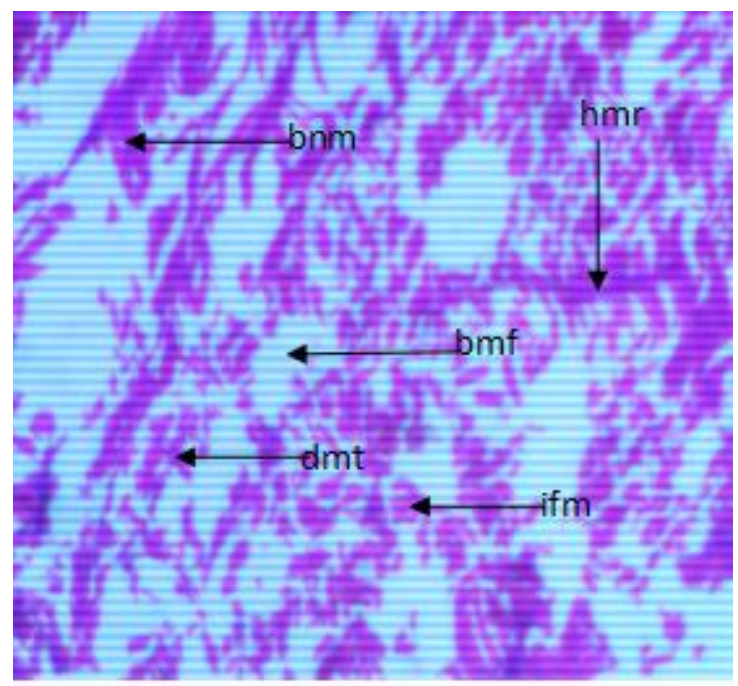

Fig. 25: Muscle section in group treated with $1.25 \mathrm{mg} 1$ Nicotina tobaccum leave extract ( 72 hours)

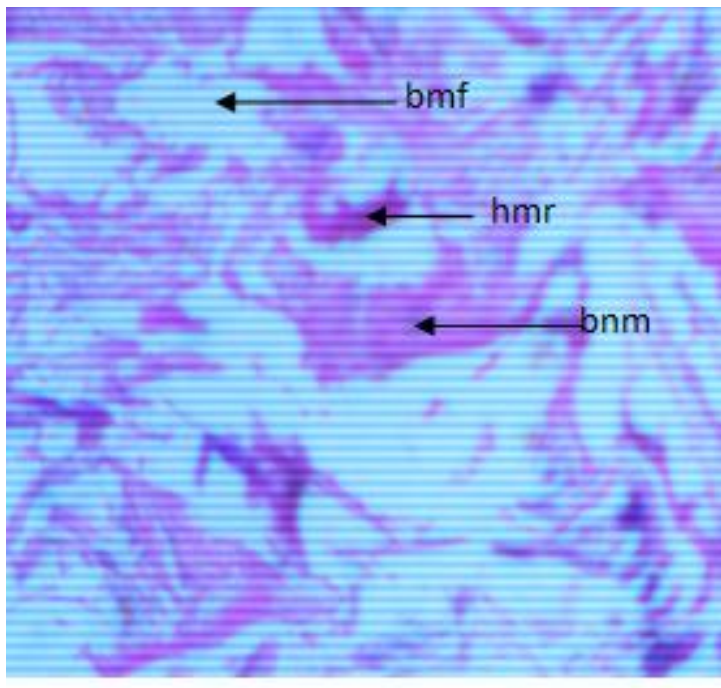

Fig. 26: Muscle section in group treated with $1.25 \mathrm{mg} / 1$ Nicotina tobaccum leave extract ( 96 hours)

Histopathology Labeling Discription

Myt - myotomes; Spm - septum; Bmf - broken myofibrils; Dmt - disintegrated myotomes; Bnm - bunding of myotomes; Ins - lesions; Hmr - hemorrhage; Ifm - inflammation.

The control group, though does not contain the tobacco extract (Nicotina tobaccum), there were noticeable changes in the histopathological features of the group as time progresses. 24 hour exposure had the normal myotomes and a septum. The myotomes and adjouining septum are uniformly arranged in a particular order. The septum is the gap between individual myotomes from where muscular fibres are attached. Though, other features were not visible from 48 hours to 96 hours, their were visible changes such as broken myofibrils, disintegrated myotomes and bondng of myotomes. Broken myofibrils were visible during 48 to 96 hours, while disintegration of the myotomes was obvious at 72 hours. Myotems actually clumbed up (bonding) at 96 hours.

Group treated with $0.25 \mathrm{mg} \backslash \mathrm{l}$ Nicotina tobaccum, no doubt showed visible aberrations progressively. These aberrations were pronounced when comapared to the preceeding control. Abnormal features noticed were lesions, broken myofibrils, bonding of myotomes and hemorrhage. During 24 hour exposure, myotoms and septum were visible and uniform as it were for the control group. However, a lesion spot and a horizontal region of breakage of myofibril were visible. At 48 hour exposure, myotome, septum and myofibrils were visibly irregular and almost completely disintergrated at 72 and 96 hours. Hemorrhage was minimal at 72 hours ,but however completely pronounced at 96 hours. There were severe bonding of myotomes and breakage of myofibril at 72 and 96 
hour exposure . Lesion was minimal. For the group treated with $0.5 \mathrm{mg} / \mathrm{l}$ Nicotiana tobaccum, aberrations visible in the micrograph of muscles of fish in the group include hemorrhage, breakage of myofibrils, disintegration of myotomes and bonding of myotomes.Histopathological features were impaired from the unset ( 24 hours). Myotomes were fewer, hemorrhage and breakage of myofibril were occurring at all the time intervals. There was visible disintegration of myotomes at 48 hours which later culminated to large mass bonding to 72 and 96 hour exposure .Breakage of myofibrils were more noticeable at this level of exposure. Lesion was absent at this exposure level.

Abnormalities noticed among the group treated with 0.75 $\mathrm{mg} / \mathrm{l}$ Nicotiana tobaccum were more obvious when compared to the preceding concentration levels. Myotomes though spatially arranged were visible at 24 hour exposure. Apart from all other abnormal features noticed at preceding levels, inflammation of muscular tissues did set in at this level of concentrations. Though not visible at 24 hour exposure, inflammation of muscle tissue gradually surfaced at 48 hour exposure and predominantly visible at 72 and 96 hour exposure. Disintegration of myotomes was predominant here as well. It was noticed at initial time interval ( 24 hours). Lesions also resurfaced here at 96 hours, though wasn't observed at $0.5 \mathrm{mg} / \mathrm{l}$ concentration. Hemorrhage, disintegration of myotomes and breakage of myofibrils were Histopathological features noticed at all the time levels.

Among the group treated with $1.00 \mathrm{mg} / \mathrm{l}$ Nicotiana tobaccum, muscle sections very distinctive effect of the tobacco extract at different exposure time intervals. At 24 hour exposure, myotomes were unduly straighted with some points of bonding. Tissue hemorrhage was also visible. At 48 hour exposure, severe inflammation of muscle tissue and disintegration of myotomes were predominant. Other notable conditions during this exposure time include

hemorrhage, breakage of myofibrils and bonding of myotomes. At 72 and 96 hour exposure, lesions were observed. Bonding of myotomes was the most obvious effect at 96 hours.

For the set of exposure with $1.25 \mathrm{mgl}$ Nicotiana tobaccum, hemorrhage, bonding of myotomes and breakage of myofibrils were noticed among all the exposure time levels. The only exception in this group was noticed at 72 hour exposure. Apart from other effects listed, inflammation and disintegration of myotomes were fresh inclusions here. They were not expressed at the other time levels. At 96 hour exposure, bonding of myotomes was the predominant effect.

\section{Conclusion}

Ethanolic extract of Nicotiana tobaccum have shown to affect the histopathological features of juvenile Clarias gariepinus.
This work and other related research findings, have presented obvious prove on the effect of Nicotiana tobaccum on histopathology, genetic and heamatological composition of aquatic animals. Aquatic life is a good biological indicator on the wellness of the environment.

Nicotiana tobaccum have been wildly applied by farmers in pond management to eliminate pests from the pond before stocking. In view of this finding, it is necessary to keep the pond totally free from figment of Nicotiana tobaccum which effects may not be visible through physical observation. In keeping to this, fish reproductive efficiency, product quality and farmers profit margin will be enhanced.

\section{References}

[1]. Delgado C., Wada N., Rosegrant M., Meijer S. and Ahmed M. (2003). Fish production by 2020. Supply and demand in changing global markets. Washington, DC, and Penang: IFPRI (International Food Policy Research Institute) and World Fish Center. P.40.

[2]. Adewumi, A. A. (2015). Aquaculture in Nigeria: Sustainability issues and challenges . Direct Research Journal of Agriculture and Food Science, 3(12):223-231.

[3]. Akinrotimi, O.A., Onunkwo, D.N. Cliffe, P.T. Anyanwu, P.E. and Orokotan, O.O. (2007a). The Role of fish in nutrition and livelihoods of families in Niger Delta, Nigeria. International Journal of Tropical Agriculture and food systems, 1(4):344-351.

[4]. Amao, J.O., Oluwatayo, I.B. and Osuntope, F.K. (2006). Economics of Fish Demands in Lagos State, Nigeria. Journal of Human Ecology, 19(1):25 - 30.

[5]. FAO. 2007. FAO Fisheries Department, Fishery Information, Data and Statistics Unit. Fishstat Plus: Universal software for fishery statistical time series. Aquaculture production: quantities 1950-2005, Aquaculture production: values 1984-2005; Capture production: 1950-2005; Commodities production and trade: 1950-2005; Total production: 1970-2005, Vers. 2.30

[6]. Kestemont, P. Toko, I. Fiogbe, E. D. and Koukpode, B. (2007). "Rearing of African catfish (Clarias gariepinus) and vundu catfish (Heterobranchuslongifilis) in traditional fish ponds (whedos): effect of stocking density on growth, production and body composition. Aquaculture, 262(1):65-72.

[7]. Noga, E. J. (1996). Fish Disease: Diagnosis and Treatment Mosby Yearbook, Inc. Weslin Industrial Drive; St. Louis, Missouri, 367pp.

[8]. Jhingran, V. G. (1983). Fish and Fisheries in India, 2nd Edition, Hindustan Publishing Corporation, New Delhi, India.

[9]. Aleem, S.O. (1987). An assessment of tobacco waste for control of the gastropod Tympandomus fuscavis 
(Linnaeus) in brackish water fish pond. Aquaculture 73: 19-25.

[10]. Hassal K. A. (1982). The chemistry of pesticides; Macmillan press, London, $\quad 372 \mathrm{p}$.

[11]. Vogues, E. (1984), Tobacco Encylopaedia. Tobacco Journal International Federal Republic of Germany, all pages.

[12]. Dani, J. A., Ji, D. and Zhou F. M. (2001). Synaptic plasticity and nicotine addiction. Neuron, 31(3):349352.

[13]. Konar, S. K. (1970). "Nicotine as a fish poison," The Progressive Fish Culturist, 32:103-104. 